\title{
Covid 19 - A Major Cause of Digital Transformation in Education or Just an Evaluation Test
}

\author{
Tsvetelina Mladenova, Yordan Kalmukov, Irena Valova \\ Department of Computer Systems and Technologies, University of Ruse, Ruse, Bulgaria
}

\begin{abstract}
This paper presents a detailed comparative analysis of the three types of eLearning (synchronous, asynchronous and hybrid) and the traditional onsite learning. The analysis considers the opinions of both teachers (the three of us) and students. We have surveyed our students twice. First time, at the end of the winter semester (end of January) - right before the Covid-19 outbreak in Europe. Then we did it again at the end of the summer semester (end of May) that coincides with the end of the first peak of the first pandemic wave in Europe. Since the first survey evaluates mostly students' attitude, the second one evaluates their real-life experience. Young people nowadays belong to the so called digital generation, so we expected that students are actually happier with eLearning rather than the traditional onsite learning. But surprisingly their opinion about pros and cons of eLearning closely resembles ours.
\end{abstract}

Keywords - e-learning, synchronous and asynchronous learning, students' attitude to e-learning, pandemic outbreak, Covid-19.

\section{Introduction}

The rapid development rate of the IT sector has been a major factor in the shift in educational practices and methodologies.

DOI: $10.18421 /$ TEM93-42

https://doi.org/10.18421/TEM93-42

Corresponding author: Irena Valova,

Department of Computer Systems and Technologies, University of Ruse, Bulgaria.

Email: ivalova@ecs.uni-ruse.bg

Received: 10 July 2020.

Revised: 06 August 2020.

Accepted: 13 August 2020.

Published: 28 August 2020.

(cc) BY-NC-ND (C) 2020 Tsvetelina Mladenova, Yordan Kalmukov \& Irena Valova; published by UIKTEN. This work is licensed under the Creative Commons AttributionNonCommercial-NoDerivs 4.0 License.

The article is published with Open Access at www.temjournal.com
Distance learning and eLearning in particular have been widely popular terms for over 20 years, related to the digital transformation in education. However, before the coronavirus pandemic, eLearning has been more or less an area of science, rather than a widespread practice. Until recently, it has been normal for students and teachers to be in a classroom, facing a blackboard or a whiteboard, but now these scenarios are unfeasible. Pandemic outbreaks, such as the COVID-19, present unique challenges to education - how to continue teaching while maintaining a physical distance. The digital transformation of education had to happen overnight. The higher education has been somehow prepared for that since students have been getting their teaching materials in electronic format for years. Furthermore, in general, it is more flexible and open for changes than lower levels of education. Even before the current pandemic, we saw universities that were heading towards the direction of distance and eLearning. However, the unforeseen circumstances made the transition much faster.

There are three types of eLearning:

- Synchronous. Usually implemented by video conferencing tools such as Zoom, Microsoft Teams or BBB. An alternative way is using real time text chats.

- Asynchronous. This type of eLearning is usually done by email, learning management systems, social media and others.

- Hybrid. A mixture of the previous two.

Synchronous eLearning closely resembles traditional onsite learning and communication. However, the visual communication is incomplete even using cameras, because the lecturer cannot effectively teach while watching many camera windows. Asynchronous eLearning, on the other hand, provides higher flexibility in terms of time management. Lecturers can teach and students can learn anywhere anytime, but it is actually more time consuming than the synchronous type of learning. Our experience shows that teaching and learning could not be effective when using synchronous only or asynchronous only approaches. Both should be implemented. 
This paper presents a detailed comparative analysis of the three types of eLearning and the traditional onsite learning. The analysis considers the opinions of both teachers (the three of us) and students. We have surveyed our students twice. First time at the end of the winter semester (end of January) - right before the pandemic in Europe. Then we did it again at the end of the summer semester (end of May) that coincides with the end of the first pandemic wave in Europe. Since the first survey evaluates mostly students' attitude, the second one evaluates their reallife experience. The supporters of eLearning usually state on media that young people nowadays belong to the so called digital generation who cannot be taught by using conservative methods from the past. So we could expect that students are actually happier with eLearning rather than the traditional onsite learning. But surprisingly students' opinion closely resembles ours.

\section{Related Work}

The computer-based learning/training from 1960s is considered to be the basis of the modern e-learning and learning management systems (LMS). During the years they have been subject to a constant research and development [5], [6], [9]. Many papers have been published providing survey analyzes and evaluation of the applicability and the benefit of elearning in the modern university education [1], [8], [10]. Until 2020, the e-learning is considered to be just a complementary support to the traditional learning. Sabou, Mihaila and Diculescu present a study on how students perceive the e-learning [11]. According to their results, $50 \%$ of the students declare they receive less knowledge from e-learning in comparison to the traditional onsite learning. Tick proposes that students of the early Z-generation should be divided into three groups: neglectful, ITconscious and skeptical [12]. A different didactical approach should be applied to each group, but according to her, the e-learning is an important part of the university teaching and it must be implemented.

In the first half of 2020, the e-learning turned out to be the only feasible way of teaching and learning. That makes it a subject of further research and evaluation of students' attitude towards it (especially after the real-life experience they gained with it). It could be expected that the long quarantine and the interruption of education would have a negative psychological impact on people in general, and in young people in particular [3], [4], [14], so continuing the learning process online was mandatory.
We are particularly interested in research related to education during quarantine or emergency situations [2], [7]. Wan outlines the main challenges of elearning during the Covid-19 crisis and suggests some changes and adaptations that should be implemented to make it better [13]. Previously, we didn't even think if students have the necessary digital devices, high speed Internet and if they, and teachers as well, are actually prepared to use digital technologies. It is becoming clear that, among other things, education has social functions as well. In times of crisis, its goals should be changed - not just to cover the material in the course's program.

In [14] teachers share their experience of elearning during Covid-19. They provide useful guidelines on how to design online courses that are easily understandable and useful for students.

Last but not least, the learning environments, the LMSs and the digital technologies also play a crucial role in teaching, learning and testing the acquired knowledge. Mahalakshmi and Radha [8] present a comparative analysis of some popular environments, such as Google Classroom, Google Forms, Google Drive, Facebook, other social networks, Zoom, email communication and specialized LMSs. The authors conclude that the virus "infected" the traditional way of teaching and learning, but elearning is an effective way to overcome the problem.

\section{Comparative Analysis of the Three Types of eLearning}

To make better and objective comparison we have defined several evaluation criteria that we find important - motivation; usefulness and acquired skills; exam grades; workload; discipline/order; professional communication and relationships.

We have surveyed students in computer science (both software and hardware) who are expected to be better prepared for online learning compared to their classmates from other fields of study.

The first survey has been filled by 201 students, mostly in their second $(27.9 \%)$, third $(24.4 \%)$ and fourth $(26.9 \%)$ year of study, and also some high schools' students and already graduated university students. $80 \%$ of the respondents are men and $20 \%$ women. The gender distribution is as expected since most of our IT students are male.

The second survey has 109 respondents that include mostly second (39.4\%) and third (43.1\%) year students and small groups of fourth year $(11 \%)$ and master $(6.4 \%)$ students. The gender distribution is similar to that of the first survey.

During the Covid outbreak we have taught entirely online by using Facebook groups (individual for each course), the video conferencing system "BigBlueButton", email and messenger. 


\section{A. Motivation and attendance}

We often hear that motivation is the key to success. And life always proves it right. Motivated students usually study more and achieve higher results. We asked students in our first survey about their motivation to study IT rather than something else. Most of them stated they are motivated by their interest in computer hardware or software (noted as "own motivation"), followed by the high level of salaries in the IT sector. Figure 1. presents a correlation between the specific motivation and the rate of class attendants. It is clearly observed that people who are keen in IT and those motivated by the salary are willing to attend almost all lectures and exercises.

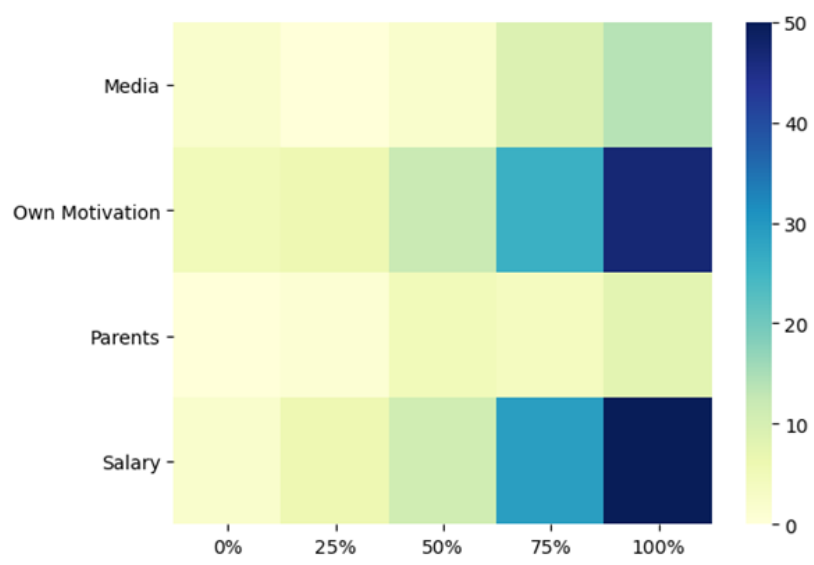

Figure 1. Correlation between specific motivation to study IT and the level of class attendance

As expected, motivation influences the attendance. It is also interesting if e-learning does the same. Since it allows students who work in companies to attend classes "while" working, we can expect to get higher attendance during the Covid semester. Our second survey asked students about the level of their attendance online and onsite. Answers given by the second and the third year students are presented in Figure 2. As seen there is no clear trend in favor of traditional or online learning. Students who are willing to attend $100 \%$ of the classes will do it regardless of the form of education. Most notable difference is between the students that will attend some of the classes and more precisely, the ones that will go to 50 or $75 \%$ of the classes. Students who are willing to go to half of the classes prefer to do it in a traditional form of learning, while students who will go to $75 \%$ of the classes prefer to do it in distance form of education.

Overall, the majority of the students think that attending classes is important and they do attend them regardless of their form. Students in higher years of education are more prone to attend $100 \%$ of the lectures.

\section{B. Usefulness and acquired skills}

Asynchronous learning leads on this criterion since it develops some very important personal skills of the students - ability to find and analyze information by themselves, better time management, ability to cope independently, improved team work and soft skills and others. But these are all learnt in the hard way by pressure and going out of the comfort zone. Probably for that reason the asynchronous form of eLearning, if used alone, gets only $12.8 \%$ approval from the students. When eLearning is inevitable (during pandemic), they prefer to use its blended form that combines synchronous and asynchronous learning. A vast majority of students (68.8\%) require synchronous form of learning as it provides real time communication with the teacher. According to $60.6 \%$ of the students, synchronous learning helps them better understand the teaching material.

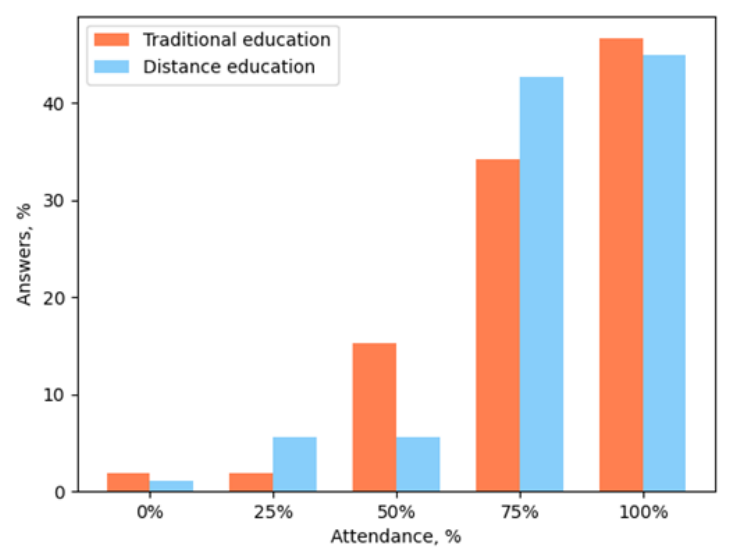

Figure 2. Dependence of attendance on the form of learning - traditional or distance

Similar thoughts are perfectly valid for the traditional onsite learning as well. If students are forced to prepare more projects and assignments by themselves they should acquire the same set of skills, even more. So, it is not about the distance education, but about the requirement to work alone (or in small groups) outside the university without constant monitoring and help by a teacher. The English educational system, for example, relies on less classroom hours (about 10 per week) and much more self-preparation and work in projects.

\section{Exam Grades}

Since exam grades represent a formal way of evaluating students' achievements, it is reasonable to compare the results they got during the traditional onsite learning and the eLearning. Figure 3. delivers a visual comparison for several courses. Results from eLearning are obtained in the summer semester in 2020, while results from the traditional onsite learning refer to students in 2019. We can clearly observe that eLearning provides higher grades for 
most courses. However, it cannot be unambiguously claimed that eLearning is better than traditional learning since higher grades could be a result from any of the following reasons:

- Each student has got more personal attention and help from the teachers during eLearning.

- The achieved results from e-learning were of students who were forced to be isolated at home during lockdown, which suggests that they spent more time studying.

- Students have had more possibilities to share and cheat during online examinations.

- The students in 2020 are better students in general than those in 2019.

We can assume that some students (motivated students who really want to study) achieved their higher grades due to the extra time and efforts they spent on learning and the more help and attention they got from teachers. But there is for sure some part of students who got higher grades because it is easier to share and cheat during the online exams.

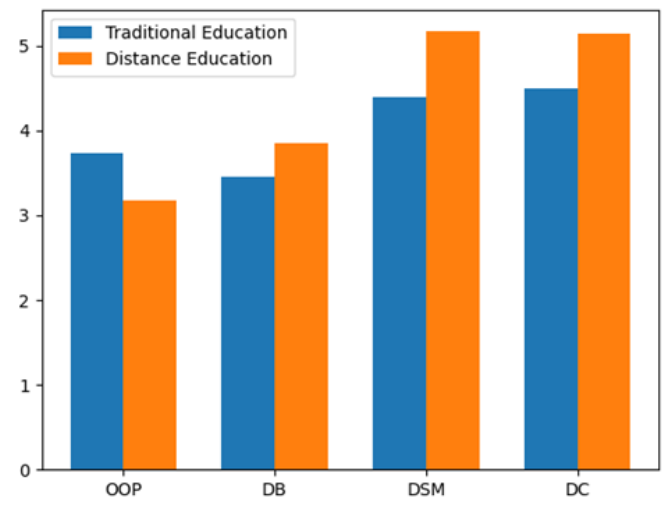

Figure 3. Exam grades from distance learning and traditional learning in four courses: OOP - Object Oriented Programing; DB - Databases; DSM - Discrete Structures and Modelling; DC - Digital Circuits

It is interesting that most students (63.3\%) expected their exam results from eLearning to be better than those they got during traditional learning (Figure 4.). However, as seen in Figure 3., their expectation is not fully supported by the real grades they have.

Few of them (only $7.3 \%$ ) do not like online exams and prefer to go on normal exams when it will be possible in the future. $16.5 \%$ of the asked students think cheating will be very easy during online exams.

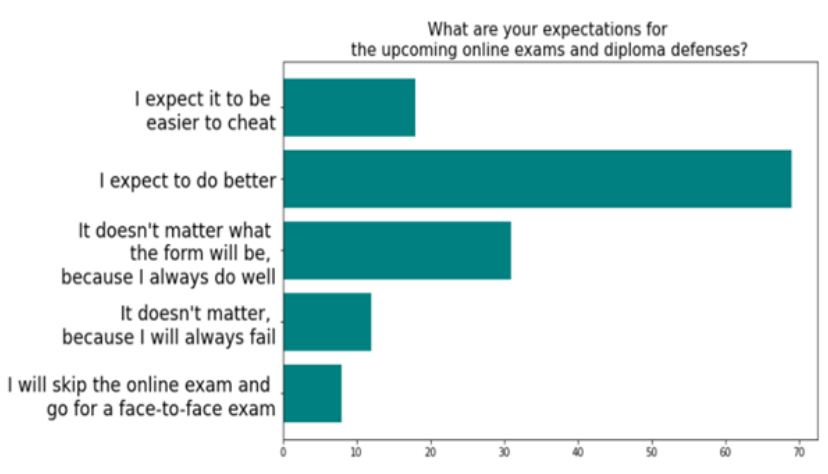

Figure 4. Students' expectation about the forthcoming exams and diploma defenses

\section{Workload}

Asynchronous eLearning provides higher flexibility in terms of time management than other ways of learning. Lecturers can teach and students can learn anywhere anytime. Whenever is comfortable for them. Sounds attractive, but it is also much more time consuming than other types of learning.

Usually tutors send teaching materials together with assignments that should be done as homework. Due to the lack of real time group communication, many issues could be left unclear. If the communication is done by email, the teacher may need to explain similar things to many students individually. But that could be easily solved by sending group messages. The most time consuming task is checking students' individual homework. On average, it takes about 30 minutes per student. However, the large amount of time is not the only problem. All activities related to eLearning (for both students and teachers) are associated with extensive work in front of a computer screen, which is dangerous for eyes and one's health condition in general.

According to $42.2 \%$ (that is the largest group) of the students, eLearning is more stressful and time consuming than traditional onsite learning. So they seem to share teachers' opinion.

Until last semester, the organization of exercises was very different. Students conducted their exercises in departments' laboratories, equipped with 8 to 10 computers (workplaces). On these computers, everything was installed and set up in advance. In most cases students preferred to work in teams of 2 or even 3. In this way, they never had to install and configure the software environments they needed on their own. Most of them didn't even bother to try to do this on their own laptops or desktops. Since the exercises usually have duration of two hours, students were working on them just within that time frame. We had no clear idea if all of the participants of the team worked, but it was always obvious that not all the students worked. 
With the new organization during the distance learning, they had to install everything themselves and each of them had to deal with the tasks from the exercises and with the implementation of the homework. This led to a much higher workload for lecturers, because we had to help everyone get everything they needed to solve the tasks (this was only in the initial weeks). With standard education, at the end of the class, we review the implementation, but it is for each team, i.e. about 3 or a maximum of 4 solutions. Not for every single student. We do not have the practice of giving homework or individual work, while in the form of distance learning we did homework every week. It seems students liked this organization of the work, because at the end of the online education $62.4 \%$ of them said they prefer to use their own laptops during classes (Figure 5.). Only $11 \%$ think it is better to use computers in the university's laboratories.

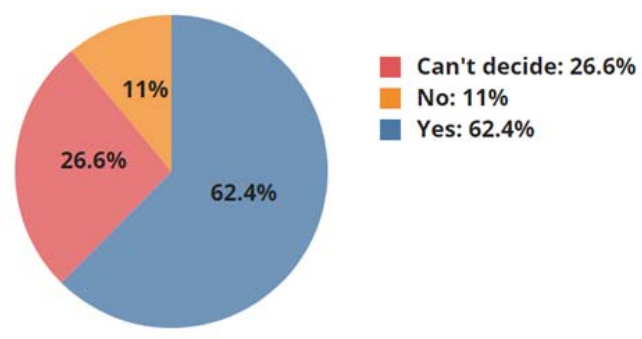

Figure 5. Students' preferences about using personal laptops (62.4\%) instead of lab computers (11\%)

\section{E. Early birds vs Nights Owls?}

It is noted that during e-learning, students are much more active in the afternoon and late evening. They sent their assignments late at evening and very rarely had questions by email or chat in the morning. The online consultations, organized at the initiative of the students, were always scheduled in the afternoon and evening. In traditional learning, students have a schedule (prepared from the university) in which their university hours are mostly until noon and less often in the late afternoon.

The evidence for the changing pattern in the students' behavior can be found not only in the answers of the surveys but also at the time of the surveys' filling. Every survey has been filled online and therefore the timestamp of the filling of every participant has been saved as well. This timestamp can be an indicator of the students' active hours and Figure 6. shows an overview of the timestamps of the surveys' fillings. Both surveys have been announced in the accepted lecturing hours. The first survey was filled while the learning process was still on-site and the students were on campus while in class. The second one was entirely conducted via social networks and emails while the students were at their homes. It is obvious that while being in a traditional form of learning the students are more engaged in the first part of the day, and being in a distance form of learning has given them the freedom to work on University assignments whenever they want, which is, by the data conducted from the survey, in the late second part of the day.

Regardless of the course that the students attended, a very particular trait of the distance learning was notable from the beginning - almost every student considered the distance form of learning as a form of on-demand learning. The normal hours for lectures and exercises were replaced with emails, messages in the social networks, even phone calls at any time of the day. Students would ask a question about a particular problem in the middle of the night, via a social network, and would expect to receive an answer very quickly. In traditional teaching/education, students very rarely use e-mail or chat to ask a question, and as their classes are once a week, they have lost interest in asking by the next exercise.

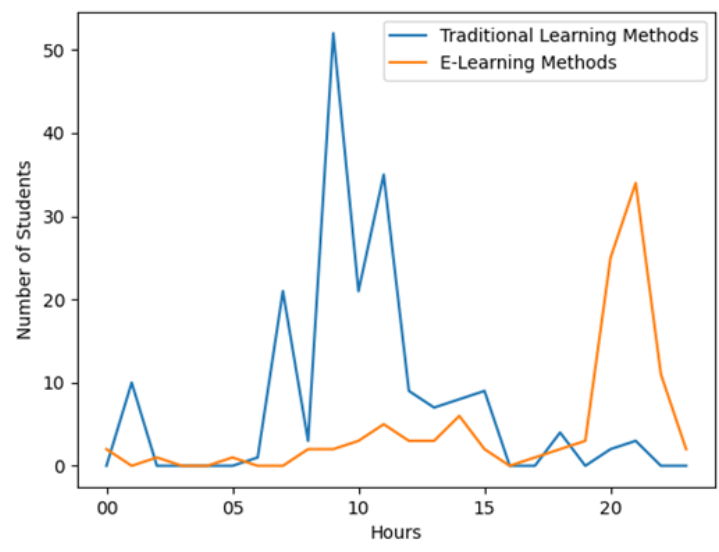

Figure 6. Students' active hours during traditional learning and eLearning

In the distance form of learning we observed a similar behavior. If the students didn't get an answer or guidance right away, they would lose interest and in many cases would quit altogether.

\section{F. Discipline/order}

Teachers and professors had to get used to the new system very quickly, be flexible and be adequately prepared:

- Depending on the questions and problems, professors must decide when to organize an online consultation or answer personal questions / emails.

- Lecturers need to show the students that they stick to what has been said about the given deadlines.

- Professors have to prepare in time different assignments and check the submitted ones in a timely manner. 
It was a big change for the students as well. Since very few of our students are used to following rules and guidelines and the majority always try to get away with minimal effort and avoid taking responsibility. This was an even harder task to adjust to. The first few weeks of distance learning were particularly difficult with students refusing to install the recommended software or complete and send homework within the specified deadlines.

In the first week, there was only one homework out of 47 that did not require additional corrections and 5 had to be returned due to just one wrong problem. All the rest had a minimal number of problems solved and required multiple returns to the students for corrections. Things improved in the second week with 9 correct assignments and the rest only requiring 1 or 2 corrections. This trend continued to improve as the weeks went by and students became much better with keeping up with the deadline too. As we never stopped assigning and requiring homework to be submitted and we spent the time checking and discussing them, the number of students completing the homework kept increasing. In addition, some students that missed the homework in the previous weeks caught up by submitting multiple assignments each week. Students were aware that their exam will involve solving similar problems and writing code, which contributed to their motivation to make sure they know how to solve them correctly. By the end of the semester, the majority of the students were keeping up with the deadlines, in particular when it came to the exams. There were procedures that required them to react within specific time limit and following an algorithm, which was completed by $90-95 \%$ of the students.

Another issue with the submitted homework was the format of their submissions. Students needed time to understand that they need to follow the guidelines on formatting their homework, what and how they had to do, their screenshots and what should the names of the submitted files be, so we can process all homework quicker and easier. Some classes required students to solve problems by writing them down on a piece of paper which proved to be the hardest to work with. The requirement was for the student to take photos of their papers and compile them into a pdf file with a specific name and submit that to us. At first, we were receiving links to a photo album where we had to find the homework ourselves, files with pages in the wrong order, random names and etc. By the end of the semester there were only a handful of students that were still unable to follow the guidelines.

\section{G. Professional communication and relationships}

It should be noted that distance learning was a unique opportunity to examine the change of the communication between the students and the lecturers and the students themselves. According to $75 \%$ of the respondents, the online communication with the lecturers is more laid-back and relaxed and they prefer it, rather than in person onsite. That is expected, but not good. Communication skills are quite important, but real-life practice is needed to be developed and improved. And while $47.7 \%$ have answered that they ask questions and participate in the online lectures, the reality is quite different.

Communication was most difficult with the students in the lower year as they did not know us since this is the first course in which we meet. They still did not know each other so well, so there was a lack of teamwork and mutual assistance between them. In 3rd, 4th year and masters - we have already taught these students, we know each other well. They have already had exams with us and they know what we expect from them and what compromises we tend to make towards them. It was extremely pleasant to work online with third year students as they are very active and initiative, cooperative and ready to help each other and help us. Third year students usually tried to explain the problems to each other on their own, working in small groups. Very often they posted their video presentations on the Facebook group with explanations of the material to help their colleagues, organized surveys to schedule consultations. Almost all of them were very open and well-meaning, they showed desire and initiative for our joint work. Everyone tried to meet the deadlines we set.

The same cannot be said about the work with second year students who we meet for the first time, since the first year of their education consist of more broad courses and not the specialized ones we teach. They had new groups, do not know each other well and cannot organize anything for the whole group. Some of them we had not even met in person before the lockdown. The online learning with them was very hard during the first few weeks. They did not show initiative and very rarely asked and shared their problems. In this way, we had no idea what was bothering them and how to help them. Gradually, after a few weeks, they became more active.

Questioned if they feel more united and at ease with each other during the pandemic, $22.9 \%$ of the students have said that they don't feel any different in the communication between themselves. $26.6 \%$, on the other hand, have stated that they feel more cohesive as a result of the distance learning. 


\section{Conclusion}

It should be accepted that the distance form of education is different from the traditional one, so it has to be treated as such. There is no doubt eLearning will continue to grow after the coronavirus pandemic. It proved to be irreplaceable way of learning during medical crises. The Bulgarian ministry of education already decided to cancel all winter flu epidemic holidays and to adopt eLearning during that period.

However, specific rules should be introduced to regulate the process of eLearning. Firstly, it is mandatory to lower the number of hours that students and teachers spend in front of the computer screen since it is dangerous for their health - both physical and mental. There has to be time for rest and other offline activities.

Teachers should be given enough time to adapt their existing and develop new teaching and examination materials suitable for eLearning and eExamination. Our personal experience shows that if a single exam assignment is given to many students at once there will be many similar or even identical answers - not necessary correct ones. Cameras and microphones help conducting an exam, but not much. Teachers can see just students' faces, but not their hands, keyboards and monitors. So cheating, and spreading and copying answers is quite easy. Individual assignments, on the other hand, make the examination much more fair and reliable. Students are busy solving their own assignments so they cannot help others. However, composing a large number of individual assignments is not easy and it is time consuming.

Security and privacy is always a concern. There is no way to prevent recording of synchronous videoconferencing sessions. Actually, students are usually doing it. However, the original voice of participants could be processed and mounted in a way that falsifies their actual words.

There are many universities worldwide that have started their digital transformation decades ago and offer full-featured online education alongside with their traditional onsite learning. For them, Covid-19 has just been a test evaluating the level of their digital transformation. Since their results seem to be satisfactory enough, many top US universities (incl. Harvard and the MIT) already announced that they will continue teaching online during the next academic year as well.
However, for most educational institutions (including secondary and high schools), the Covid-19 appears to be a major cause to initiate a large-scale digital transformation. There is an enormous support from both politicians and society towards digitizing and adapting all teaching materials and provide students/pupils from poor families with high speed Internet and the necessary devices.

\section{Acknowledgements}

This paper is supported by project 20-FEEA-01 "Methods and tools for multimedia content analysis, and automated document and big data processing”, funded by the Research Fund of the "Angel Kanchev" University of Ruse.

\section{References}

[1]. Aulia, F., Wahyudin, D., \& Rusman, R. (2018). Lecturers Perceptions about E-Learning on the Development of the Indonesian Qualifications Framework Curriculum. In Proceedings of the 1st International Conference on Science and Technology for an Internet of Things. European Alliance for Innovation (EAI).

[2]. Basilaia, G., \& Kvavadze, D. (2020). Transition to online education in schools during a SARS-CoV-2 coronavirus (COVID-19) pandemic in Georgia. Pedagogical Research, 5(4), 1-9.

[3]. Brooks, S. K., Webster, R. K., Smith, L. E., Woodland, L., Wessely, S., Greenberg, N., \& Rubin, G. J. (2020). The psychological impact of quarantine and how to reduce it: rapid review of the evidence. The Lancet.

[4]. Cakir, Z., \& Savas, H. B. (2020). A Mathematical Modelling Approach in the Spread of the Novel 2019 Coronavirus SARS-CoV-2 (COVID-19) Pandemic. Electron J Gen Med. 2020; 17 (4): em205.

[5]. Camilleri, M. A., \& Camilleri, A. C. (2017). Digital learning resources and ubiquitous technologies in education. Technology, Knowledge and Learning, 22(1), 65-82.

[6]. Sousa, M. J., Cruz, R., \& Martins, J. M. (2017). Digital learning methodologies and tools-a literature review. Edulearn17 Proceedings, 5185-5192.

[7]. Lim, E. C., Oh, V. M., Koh, D. R., \& Seet, R. C. (2009). The challenges of" continuing medical education" in a pandemic era. Ann Acad Med Singapore, 38(8), 724-726.

[8]. Mahalakshmi, K., \& Radha, R.(2020). COVID 19: A Massive Exposure Towards Web Based Learning. Journal of Xidian University, 14(4), 2405-2411. https://doi.org/10.37896/jxu14.4/266. 
[9]. Dina, R., Onete, B. C., \& Albăstroiu, I. (2018). eLearning Paradoxes. Considerations about e-Learning Future. In The International Scientific Conference eLearning and Software for Education (Vol. 4, pp. 145-150). " Carol I" National Defence University.

[10]. Radha, R., Mahalakshmi, K., Sathis Kumar, V., \& Saravanakumar, A. R. (2020). E-Learning During Lockdown of Covid-19 Pandemic: A Global Perspective. International Journal of Control and Automation, 13(4), 1088-1099.

[11]. Sabou, G., A. R. Mihaila, A. Diculescu. (2016). Students perception about e-Learning platforms. In Proceedings of the International Conference EdPROF 2016, Bucharest, ISSN 2285-0910, 179-185.
[12]. Tick, A. (2019, April). Evaluating e-learning acceptance and usage motivation including IT Security Awareness amid $\mathrm{Z}$ generation Hungarian students with xTAM. In 2019 IEEE 23rd International Conference on Intelligent Engineering Systems (INES) (pp. 000137-000142). IEEE.

[13]. Wan, Ya Shin. (2020). Education during COVID19., Retrieved from: http://www.ideas.org.my/briefideas-no-19-education-during-covid-19/ [accessed: 17 June 2020].

[14]. Ocak, M., (2020). What we learned about distance education during Covid-19?, Retrieved from: https://epale.ec.europa.eu/en/blog/what-we-learnedabout-distance-education-during-covid-19 [accessed: 20 June 2020]. 